Article

\title{
Influence in Technological Innovation Spaces: A Network Science Approach to Understand Innovation for Sustainability in the Global South
}

\author{
Daniel Schmitt ${ }^{1, *}$ and Chisenga Muyoya ${ }^{2}$ \\ 1 Department of Geography, University of Bonn, Meckenheimer Allee 176, 53115 Bonn, Germany \\ 2 Department of Geography, University of Sheffield, Western Bank, S10 2TN Sheffiel, UK; \\ cmuyoya1@sheffield.ac.uk \\ * Correspondence: Daniel.schmitt@uni-bonn.de
}

Received: 15 January 2020; Accepted: 25 February 2020; Published: 1 March 2020

check for updates

\begin{abstract}
The number of scholars working on transition concepts in the Global South is rapidly increasing. In this context, a substantial amount of research output particularly focusses on niches and how they affect transition towards sustainability in a wider framework of the multi-level-perspective. At the same time, there is a growing interest in digital technology and its effect on sustainability challenges. In this article, we combine the two fields, and by utilizing social media data, we create an innovative network science approach to analyze the production environment of digital innovations in Africa. We focus on three innovation hubs that we conceptualize as niches and innovation intermediaries that not only create communities to develop, test and implement new technology but also function as networks to discuss and form new ideas around innovations. Our key findings show how local communities are embedded in larger innovation structures. The connections between local stakeholders and global actors are predominantly created through bridge actors, who hold key positions in their communities. With tools from network science, we demonstrate that these linking elements can regulate and steer discussions and therefore, strongly influence digital niche environments. Utilizing geographical location data, we can also see that the online space of technological innovations in Africa is heavily cantered in urban areas.
\end{abstract}

Keywords: Twitter research; influence analysis; sustainability; transition; network science; innovation; tech hubs; Africa; ICT4D

\section{Introduction}

With the establishment of sustainability as a key goal for global development, we see a growing integration of core transition concepts for research on socio-technical systems in the Global South (Due to the complexity of societal structures, the term Global South is used to emphasize power relations and inequalities within the research context rather than using simplified and normative terms, such as "developing countries" or "third world countries"). For system changes towards sustainability to be effective, research from transition studies implies that interlinkages between institutions, socio-cultural systems, the economy and technology are important to understand and govern such transformations [1,2]. As Wieczorek [3] pointed out, transition research in the Global South is highly influenced by strategic niche management approaches (SNM) and the multi-level-perspective (MLP) [3,4]. Within the MLP framework, niches are characterized by the provision of protection from the dominant market and societal dynamics, therefore, enabling and fostering new radical innovations [5,6]. The focus on niche environments comes as no surprise as it not only builds on established major research from transition scholars in western hemispheres but also applies to dynamic and fast-changing societal settings that are prevalent in the Global South. Most of this conducted 
research on niches in the Global South deals with a variety of topics of which energy, agriculture and mobility are the most dominant ones [3]. At the same time, there has also been a growing interest in the digital economy and its associated information and communication technologies (ICT). El Bilal and Allahyari [7], for example, looked at agriculture food chains and integrated ICT's contributions to sustainability outcomes. Another example can be found in research on sustainability transition and the impact of the sharing economy fueled by digital innovations $[8,9]$. Simultaneously, a large margin of technological developments in sustainability sectors also stem from new ICTs or are influenced by important digital innovations that enabled stakeholders to develop new sustainability models. Examples of this can be found in smart city research that builds on data connectedness and the Internet of Things (IoT) [10] or transition perspectives in new energy systems, such as smart grids [11].

In the Global South, and especially in Africa, digital technology is often associated with tech and innovation hubs that have emerged as niche actors with the mission to solve economic, social and ecological problems with the tools of digital entrepreneurship and innovative business ideas [12]. Their number on the African continent has grown to 618 in 2019, which is an increase of $39.8 \%$ to the 442 in 2018 [13]. The growing attention and rapid expansion of innovation spaces not only show the dynamic behind digital technologies but also highlight the high expectations for development processes, including pathways towards sustainable development. These new developments also demonstrate that digital technologies are no longer only imported but innovation hubs establish local development environments to create home-made and context-specific solutions [14]. But as much as many countries in Africa leapfrogged their way to wide accessibility and use of ICTs, comprehensive digitalization is still rare, and many niche actors have trouble to upscale and establish their technologies [15]. And although the quantity of those hubs is constantly increasing, its impacts and actual outputs are highly debated, asking for more in-depth research in this field [16-19].

In a more and more digitalized world, these processes clearly demonstrate two trends: First, the growing importance of understanding local born digital innovations for sustainability research in Africa. Second, digital technologies from and for Africa are often connected to innovation hubs that create niche environments for new technologies. With the rise of sustainability research that builds on digital technology, we want to contribute to this ongoing debate by exploring niche actors around innovation hubs and their networks that convoy innovation processes in Africa. Understanding the development and production environment in the form of those hubs is, therefore, of key importance to discern where new ideas and practices for sustainability models that encompass digital elements stem from.

We investigated those digital innovation networks by looking at the online activities around three different innovation hubs in Africa, namely the BongoHive Hub in Lusaka (Zambia), the Innovation Village Hub in Kampala (Uganda) and the iSpace Hub in Accra (Ghana). We selected these hubs with the help of AfriLabs as three representative case studies from Southern, East and West Africa. AfriLabs is a network organization that connects all major innovation centers from across the whole African continent and organizes reoccurring conferences amongst key leaders in digital innovation communities. Because we wanted to understand the context of innovation places that contribute to and influence digital development processes, we utilized methods from social network analysis (SNA). As people tend to cluster in groups "as a result of interaction opportunities defined by places where people meet" [20] (p. 529) and these groups are important in the establishment of similar views amongst all members [20], SNA offers us a suitable framework for our methodological approach. We followed a tradition of several case studies that already connected SNA to innovation studies (e.g., [21,22]), proving its unique value within the innovation context. In recent years, there has also been a growing interest in utilizing social media networks, as online interactions provide new data for the formation of communication structures and the formation of views and opinions [23]. For our case study, we, therefore, mined Twitter data (97,040 tweets) that cover the whole Twitter activity around the selected hubs for a duration of three years (time frame: 15 May 2016 00:03:00-14 May 2019 23:30:00). We asked what networks these hubs are part of and how we can uncover and analyze 
influences within the networks. We, therefore, used a spatial and scalar perspective on the online space of digital networks and contribute to a better understanding of innovation hubs in Africa. Thus, this article adds two valuable insights to sustainability research: First, it introduces an innovative way of dealing with large social media data to analyze and understand its influence in niche environments. Second, it contributes to current discussions on digital innovations for sustainability research in Africa.

The structure of this article is as follows: First, we give an overview of innovation spaces in Africa and linked research to those technology hubs before we discuss our spatial and scalar approach to network research. We conclude the theory part by summarizing the fundamentals of network science before briefly highlighting Twitter research and the relevance of our approach to transition research on socio-technical systems. Before we present the data and end with a discussion of our results, we also elaborate on our methods, including giving an access-to-all code.

\section{Innovation Hubs in Africa}

Innovation hubs are physical and communal spaces where technology and entrepreneurship enthusiasts gather to obtain and share knowledge, skills and resources that are often used to develop ideas and build businesses [18]. Tech hubs employ hybrid income generation models that include public and private partnerships, paid co-working space, consulting services and paid skills development. They also consolidate their efforts by building on national, regional and continental peer learning networks [24]. The last decade has seen the emergence and rapid growth of technology hubs across Africa. This growth has been linked to three key factors: improved ecosystems and operating environments that attract and support technology advancement, increased volume of venture funding raised by tech startups and pre-existing hubs re-working their business models to better suit their markets [25].

The general discourse around innovation hubs is broadly optimistic, with hubs largely being theorized by their potential output - the ability to drive economic growth in Africa by linking motivated entrepreneurs with the business skills, technology and networks that they need to thrive [26,27]. However, similar to the startups they support, tech hubs can also be fragile as empirically observable by the 150 hubs that ceased operations between 2016 and 2018 [24]. This tension between tech hubs holding vast economic potential, yet being vulnerable to closure, has contributed to research focused on the sustainability of tech hubs [28,29]. Research has also underscored the importance of analyzing hubs beyond economic inputs and outputs by understanding their impact on aspects of human development, such as wellbeing and agency [12]. More recently, there has been an increased emphasis on understanding the processes, underlying ideologies and value systems within tech hubs and the contexts they operate in [30,31]. From an innovation perspective, Friederici [17] used the concept of innovation intermediation to consider both the process and outcome of tech hubs. This approach provides a framework to analyze how technology hubs serve as intermediaries between entrepreneurs and enabling actors (such as corporates and investors), and in doing so, change the underlying social structures in ways that shift economic opportunities that technology entrepreneurs can access [16]. In the discussion of our data, we adopted this approach and used its underlying stakeholder network logic to understand different stakeholders' positions in this complex system structure.

\section{Spatial and Scalar Network Approach}

From a theoretical perspective, there has been an increased interest in spatial and scalar dimensions of innovation processes. Notably, after Lawhon and Murphy [32] suggested broader research agendas for the field and Hansen and Coenen [33], Bridge et al. [34] and Truffer and Coenen [35] collected, sorted and analyzed conceptual frameworks for geographical aspects of innovation, a large variety of space and scale concepts have been used for a growing number of empirical research. In this regard, several clusters inspired by human geography have emerged. They range from evolutionary economic geography, conceptualising space as geographical dissemination of routines [36] or relational perspectives of political economy in energy transition [37] to place-making approaches that emphasize 
political process and their influence over the progression of socio-technical systems [38]. Following the concept of innovation intermediation, we approached our research from this relational perspective and defined space as a relation between objects [39]. In our case, this translated to different individual and institutionalized actors who connect through online tools and form a relational network. In the same sense, we did not define scale as real material existence but instead see it as a fluid process that is "a way of framing our understanding of the world" [40] (p. 229). As a result of network research, scale, therefore, does not consist of static analytical categories that can be clearly delineated. Scale, rather, emphasizes that the local and the global are both part of the same network and have no hierarchical order [41]. Consequently, instead of analysing relations through static categories, the interconnectivity of scale shifts to the center of attention.

Concluding our practical and theoretical context, we identified four above mentioned trends that can be summarized as follows: First, transition scholars are more and more interested in understanding sustainability transformations in the Global South [1]. Second, digital technologies fueled by rapid developments and diffusion of ICTs have brought up the question of what role digital technology plays as a driver behind sustainability transitions in the Global South [2,3]. Third, in Africa, actors in the field of digital innovations are often linked to institutionalized innovation hubs that, therefore, play a key role in the innovation process of digital technologies [16,17]. Fourth, understanding spatial and scalar dynamics has proven to add valuable insights into innovation processes. Innovation hubs are embedded in complex global networks that influence how digital innovations are shaped [42]. The structure of those hubs can be constructed as innovation intermediaries, which helps in understanding the internal dynamics of hubs through a relational space and scale conceptualization.

In this paper, we, therefore, analyzed three innovations hubs in Africa, namely BongoHive (Zambia), Innovation Village (Uganda) and iSpace (Ghana). By looking at their Twitter activity and associated networks, we aimed to uncover some key drivers behind digital innovations in Africa and what influence networks exist around those highly active innovation spaces. We focused on the questions of what the production environments of digital innovations in Africa look like and what position and influence actors in the (niche) production of digital technologies occupy, create and use. By doing so, we want to encourage further network research around digital technology and its production environment in Africa as digital innovations play an increasingly important role in many topics of transformation research. Additionally, this network approach to online spaces and niche research can also be used in other contexts and introduces new methodological perspectives for sustainability science.

\section{Methods}

Twitter is a social media platform that enables users to distribute short messages (so-called tweets) that contain up to 280 characters (Twitter changed the character limit from 140 to 280 in 2017), in addition to an optional media file, such as a GIF, a video or a picture. What distinguishes Twitter from other online communication tools is the very specific code-enabled practice behind each tweet. Schmidt [43] (p. 5) described this code between social ties and lingual references as a way to "structure the flow of communication and to filter information". The fundament for communication on Twitter is based on three basic concepts. First, each account can follow other accounts and see their tweets on its own timeline. This way each account creates a network of following and followed accounts that determine the composition of the account's timeline (start page). Second, there are three different ways of communicating with Twitter: creating a new tweet, replying to an existing tweet and retweeting a tweet (and therefore, forwarding a tweet to its own audience). Third, with the use of a hashtag (\#) that is followed by a term or phrase, it is possible to make your message searchable by the platform and therefore, enable visibility outside the initial account's network. In a similar way, the @-sign allows the tagging of other accounts and is used to reply or address another account.

Research with and about Twitter is constantly growing. Especially after Weller et al. [44] collected and organized fundamental concepts of the digital platform for social research purposes, many research 
fields have experimented with the use of Twitter data (see [45-47]). Understanding how actors use the online space to connect and communicate in combination with a specific topic, such as disaster risk [48], tourism [49] or supply chain practice [50], has been the central drive behind this move. From an abstract point of view, this comes as no surprise as Twitter activity creates a social network between a variety of actors and institutions. Social network analysis approaches concentrate on these created connections and "map and measure formal and informal relationships to understand what facilitates or impedes the knowledge flows that bind interacting units" [51] (p. 1). Due to its constant growth in user bases to 330 million in 2019, tapping into these large datasets and uncovering dynamics in complex social systems can be a valuable addition to more established research methods.

As Bruns and Moe [52] elaborated, Twitter can be used for a large variety of communication types. Following their categorization of communication types, we mainly find communication-based on hashtags that encircle the discussions on the three innovation hubs from a macro perspective. Here the audience of tweets is specifically bound to a hashtag that has the potential of carrying the message outside of one's own follower sphere and therefore, can be described as a public statement. In our dataset, we generally saw hashtag-based exchanges but acknowledge that some of the tweets also have a small-scale reach with no use of hashtags and only circle within a specific account's followership. For our network analysis, we filtered out some of those exchanges to create better visualization for the core connections and therefore, ignored isolated communities.

Besides using most common terms, bigrams, most active users and other basic metadata that we predominantly extracted from the tweet's text, in this study, we utilized the Twitter data with methods from network science. According to Kenett and Havlin [53], network science is one of the most active fields in interdisciplinary research and shows that connections between different entities in complex systems can be analyzed by not only looking at the entity itself but also at their position and connection within a network [54]. Network science works with the connections between entities and focuses on the structures and relations between nodes [55]. In network science, a node is a representation of an entity that stores data. Nodes are connected to each other via edges that, therefore, function as a link between nodes and can also store additional data in the form of weight [56]. In our case study, each node was a representation of one Twitter account that actively participated in the form of writing or retweeting information about one or more of the selected innovation hubs. Edges show in which ways those accounts replied, retweeted or mentioned other accounts and vice versa.

\section{Data Characteristics, Preparation and Processing}

Our whole code for downloading and processing the data can be accessed on Github (https://github. com/DanSchmitt/Influence-in-online-spaces-Mapping-Twitter-networks-of-innovation-hubs). To better understand the production environments of digital innovations in Africa and analyze the position and influence that actors in the (niche) production of digital technologies occupy, create and use, we downloaded all tweets that contain the name of at least one of the three targeted hubs. This included hashtags about the hubs, replies to a discussion about a hub and retweets that talked about at least one of the hubs. For the download, we accessed Twitter's application programming interface (API) through the Full-archive endpoint via a Python-based library called Tweepy. The time frame was set to 15 May 2016-14 May 2019, covering 3 years of Twitter data about our selected case study. With these settings, we captured the first tweet on the 15th of May 2016 at 00:03 h and the last tweet on the 14th of May 2019 at 23:30 h with 14,665 total unique users and 97,040 individual tweets.

The tweets are stored in JavaScript Object Notation (JSON) format. JSON is built on a collection of name and value pairs, with attributes and associated values. Each object (tweet or user) encapsulates attributes that contain information about the object. These attributes range from unique user ID to timestamps, follower counts, geodata, language or messages (tweet text) and many more. Due to restrictions from Twitter's privacy terms and conditions, we are not allowed to publish our data, but a sample of the tweets' metadata structure can also be found on our Github. 
As a way of extracting relevant information, we approached the Twitter dataset from two different angles. First, we analyzed fundamental quantities. Those are total tweet count, language used in tweets, unique users, average number of posts per user, most active users, unique hashtags used and the most used hashtags. We chose to extract this information to get a good overview of our dataset and determine the most active users in comparison to average users and most discussed topics through hashtag analysis. As a second step, we extracted the text from tweets and analyzed the most used terms and most used bigrams by using techniques and tools from Natural Language Processing [57]. A bigram is a string of two adjacent words and demonstrates which two words were most often used together. We further analyzed co-occurrence of terms in full tweets that in contrast to bigrams do not have to be in a sequence but could also be segregated by other words in the same Tweet. The information provided by this method also helped us in understanding broad topics and content of messages.

For us to understand the regional origin of tweets and how influence in online spaces is connected to geographical areas, we created a heat map for the activity on the African continent. Out of the 14,665 total unique users, 12,312 tweeted with geodata, including the voluntary location information in the profile information. Two hundred and eighty-six (2.32294\%) locations resulted in an error due to unclear information for Google maps API, e.g., "Pearl of Africa". For the heatmap, we utilized tools from Google fusion tables using the number of Twitter accounts with no weighting on individual tweet numbers.

To get a better understanding of the network structures within our dataset, we used a variety of algorithms. For layout purposes of all three graphs, we used the ForceAtlas2 method that is a generic way of spatializing data [58]. For our mention network visualization, we used the modularity algorithm to detect communities within our network [59]. The modularity of the network part is calculated as a value between -1 and 1 "that measures the density of links inside communities as compared to links between communities" [60] (p. 2). This method provided us with a better understanding of the digital communities that are formed on Twitter and highlights the interconnectivity between them. For our replies' network visualization, we used the betweenness centrality algorithm by Brandes [61] to find the shortest paths between nodes that in return, provides a useful measurement of centrality within a network. As discussed in-depth by Riquelme and González-Cantergiani [62], centrality in Twitter networks explains the position of accounts that determines control over information flow within the network. This method in combination with further knowledge of the account itself, enables us to understand the significance of the account when it comes to its range of influence, its coverage and its control over online discussions. In connection to tweets that are replies to other tweets, this method gives us a good understanding of whose discussion inputs are central in the network and who can regulate and steer certain talking points due to this power [63]

Visualization of the networks and the above-elaborated algorithms was done in Gephi. Gephi is a network analysis and visualization software that was introduced by Bastian et al. [64] and is used in a variety of scientific fields, such as biology (see, e.g., [65]), media studies (see, e.g., [66]), or economics [67]. We used Gephi to create an easy to understand visualization of connections between different Twitter accounts, including intensity, cross-linkages and position within the whole network.

Of course, there are some limitations to this case study and the involved methods that we want to address before presenting the results. First, we cannot assume that all relevant stakeholders of the inspected innovation networks are regular Twitter users and put effort into participating in online discussions around their work. Because of this, we compared and discussed our outcomes with experts from the three African innovation hubs and made sure to have a good representation of active stakeholders in our data before conducting the actual analysis. Second, we chose three innovation hubs with the support of AfriLabs that represent Southern, Eastern and Western Africa. Although we were very careful to find good case study examples, some hub's innovation communities are quantitively larger than others and therefore, had a larger representation in the data set. The final limitation is concerned with the Tweets' content. In our base analysis, we were only able to analyze alphabetical 
characters, numerical characters and emojis. Therefore, our study did not factor in any content in the form of posted pictures or videos.

\section{Results}

As briefly mentioned above, the results are structured into two sections. The first one is based around fundamental metrics of the dataset, while the second one focuses on network analysis and understanding relationships within the online space of the three inspected innovation hubs.

The dataset contains a total of 97,040 Tweets with the first Tweet posted on the 15th of May 2016 at 00:03 h and the last Tweet posted on the 14th of May 2019 at 23:30 h. Of the collected tweets, $95.88 \%$ (93042) were in English.

\subsection{User Metrics}

While the average account posted 6.62 Tweets during these three years, Figure 1 illustrates the detailed distribution of the tweets in connection to the 14,665 unique users in the form of a histogram. With most users (between $10^{1}-10^{4}$ ) only tweeting between 1 and 100 times, we can see that the large majority of tweets come from a wide Twitter user base. In contrast, the top 10 most active accounts made up for $14.98 \%$ of all tweets, while they only represent $0.07 \%$ of the total user base. This highlights two types of users: 1) users who only casually participate in the active shaping of online discussions and exchange of ideas ( $<100$ tweets in 3 years), 2$)$ users who are very dominant and visible in the online space of the three innovation hubs ( $>100$ tweets in 3 years).

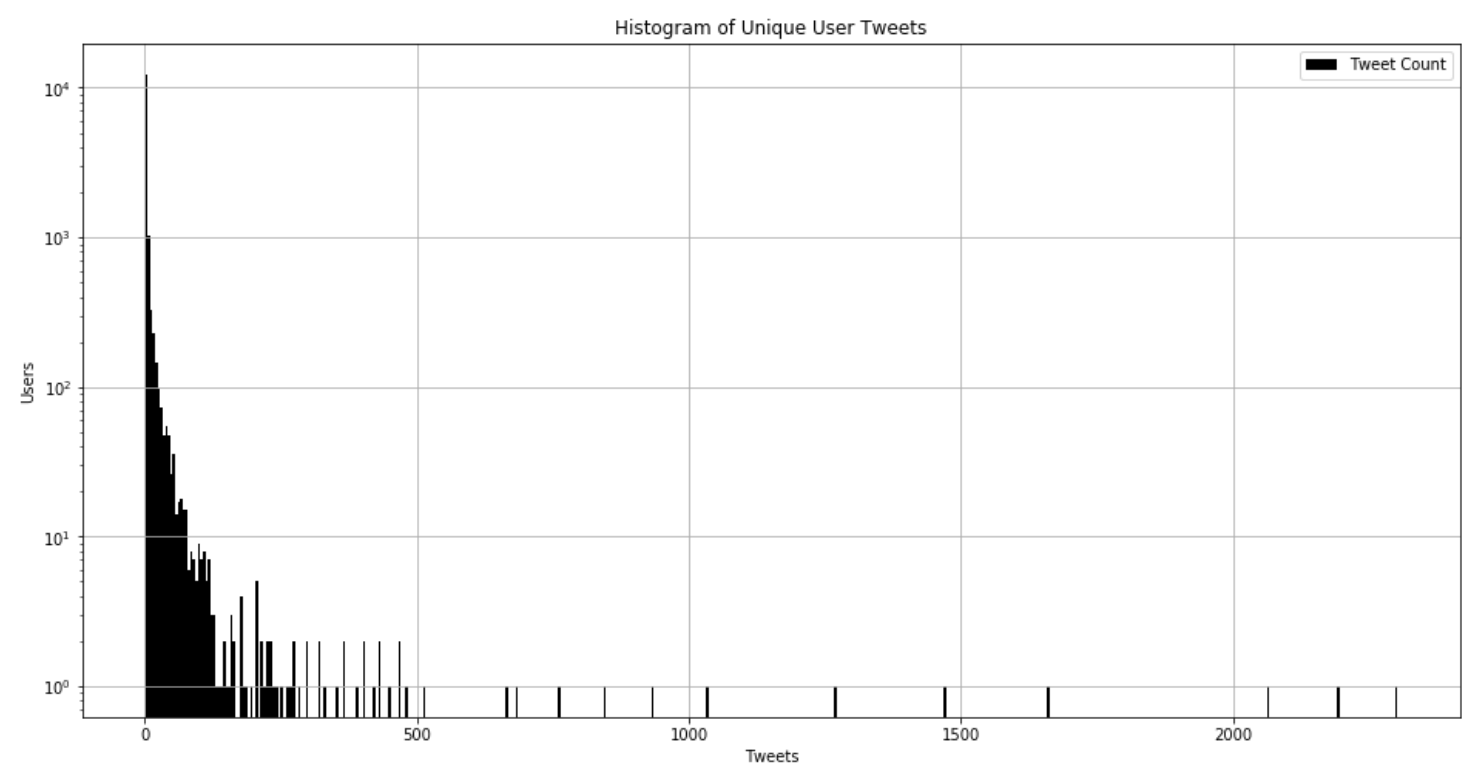

Figure 1. Histogram of unique user Tweets.

Considering these few user accounts for such a large percentage of all tweets, it is worth looking at them in more detail. Table 1 gives an overview of the top 10 users that tweeted about at least one of the three innovation hubs. Not surprisingly, the official accounts of the hubs were amongst those highly active users, with InnovationVilla and iSpaceGh at Rank 2 and 3 with 2193 and 2067 tweets and BongoHive at Rank 8 with 935 tweets. 
Table 1. Most active users.

\begin{tabular}{|c|c|c|c|}
\hline Rank & Top Users & Tweet Count & $\begin{array}{l}\text { Twitter Descriptions (Data Retrieved } \\
23 \text { May 2019) }\end{array}$ \\
\hline 1 & UnlockingWAT & 2302 & $\begin{array}{l}\text { @Google Global Diversity Award Winning } \\
\text { Program Supported by @ComicRelief } \\
\text { Partnered with @iSpacegh to empower } \\
\text { \#women to \#innovate through \#technology }\end{array}$ \\
\hline 2 & InnovationVilla & 2193 & $\begin{array}{l}\text { For \#entrepreneurs and those who believe } \\
\text { in them! \#TIV }\end{array}$ \\
\hline 3 & iSpaceGh & 2067 & $\begin{array}{l}\text { An \#Innovation \#Hub for the Tech \& } \\
\text { \#Entrepreneurial Community in \#Ghana. } \\
\text { Entrepreneurs and Startups get to Meet, } \\
\text { Network, Work and Share ideas here. }\end{array}$ \\
\hline 4 & jkeyison & 1660 & $\begin{array}{l}\text { Co-Founder } \\
\text { @iSpaceGH|\#TechInnovator|\#Marketing \& } \\
\text { \#BizDev Specialist|Advocate for } \\
\text { \#WomenInTech josiah@jkeyison.co }\end{array}$ \\
\hline 5 & eGotickets & 1472 & $\begin{array}{l}\text { Africa's fastest growing event ticketing } \\
\text { house. } 8 \text { eXperience it here! Dial } * 713^{* 33 \#} \\
\text { or visit https://t.co/64kYgrBDAt } \because \text { Call } \\
\text { +233 } 242825622 \text { \#Events \#People }\end{array}$ \\
\hline 6 & myraclera & 1271 & $\begin{array}{l}\text { Fun loving, kids loving, music loving, } \\
\text { dance loving, sadist hating, God fearing, } \\
\text { phenomenal African Genius. } \\
\text { Volunteering enthusiast! \#Tadi is bae! }\end{array}$ \\
\hline 7 & ajo_social & 1036 & $\begin{array}{l}\text { Our aim is to connect social Problems to } \\
\text { Social entrepreneurs and social } \\
\text { entrepreneurs to social problems. } \\
\text { We also connect volunteers to opportunities }\end{array}$ \\
\hline 8 & BongoHive & 935 & Lusaka's Technology \& Innovation Hub. \\
\hline 9 & iamrobotboy & 845 & $\begin{array}{l}\text { Building your online presence, } 280 \text { xters at } \\
\text { a time|\#Netizen|I wear \#Selections from } \\
\text { @1stselections|Hubspot Inbound Marketing } \\
\text { cert.|Tweets are my own }\end{array}$ \\
\hline 10 & RunisMedia1 & 761 & $\begin{array}{l}\text { Building \#DigitalMarketing experiences } \\
\text { with } \bigcirc \text { for great \#brands|Email: } \\
\text { runismedia@gmail.com }\end{array}$ \\
\hline
\end{tabular}

The most active account was 'UnlockingWAT', an initiative "to equip women with Coding, Business Management, Professional Networking and Pitching Skills and access to Funding to kick start their businesses" (Website https://www.unlockingwat.com/). 'UnlockingWAT' offered three courses on business, tech development and graphic design in addition to a mentorship program for women and girls. It is supported by the British charity organization comic relief and partnered with the innovation hub iSpaceGh. The account 'jkeyison' (Co-founders of the iSpace Hub) was a prime example of another trend we saw in the most active user analysis. Amongst the most active accounts, there was a large number of either founders of the innovation hubs or founders of key initiatives that are rooted or located at the hubs. Another example would be 'lukonga', who is Co-founder of BongoHive or 'mbuyu_', who is a co-founder and community lead at Facebook Developer Circles Lusaka that holds its regular meet-ups in the meeting room of the BongoHive hub. In the most active accounts, we also found the two companies 'eGotickets' and 'RunisMedia', which are both based in Ghana and have ties to the iSpace innovation hub. While 'eGotickets' distributes and sells tickets for events in 
Ghana, RunisMedia is a digital marketing agency. The account 'iamrobotboy' was also active in the same domain and intensively posts information on digital marketing. The accounts 'myraclera' and 'ajo_social' belong to the same person and focus on volunteering and social enterprises but have no working online presence, and we could find any actual activity outside of social media.

\subsection{Hashtags \& Terms}

Hashtags are indicated with the \#-symbol and index key terms, phrases, or subjects. It enables Twitter users to easily follow a discussion they are interested in by allowing them to use it as a link and thereby search for the same hashtags in other tweets. Hashtags are, therefore, an easy way to analyze the topic of a tweet on the most general level. In our dataset, there were a total of 3905 unique hashtags. We could filter out 5 different patterns that were reoccurring when looking at the most used hashtags: (1) country/continent names, (2) events or conferences, (3) entrepreneurial and tech terms, (4) discussion campaigns, (5) tech initiatives and programs. The country and continent names \#Zambia, \#Ghana, \#Uganda and \#Africa were used in $6.31 \%$ of all tweets, highlighting how important regional geographies are for the innovation community and how much focus lies on the respective country, the African continent and contextual implementation of technologies. This focus can also be observed with geodata and is further elaborated below. The second pattern circulated around events that were closely connected to the technical innovation communities. Examples are '\#afrilabsag', which is used for the annual gathering of AfriLabs (network of African innovation hubs) or \#gew2016, the Global Entrepreneurship Week 2016. These patterns also matched our findings for most frequent terms, bigrams and term co-occurrences. Terms such as 'sign up', 'apply for' and 'join us' indicated invitation tweets to events or programs that were often also containing the bigrams 'at' 'BongoHive', 'iSpaceGh' or 'Innovationvilla'. The third pattern highlighted general terms that surround the tech and business community in the hubs. Amongst the most used hashtags, \#startup, \#tech, \#IoT, \#python or \#coworking clearly showed the adoption of global terms that surround the digital innovation community and also gave us a good understanding of community affiliation (startups, coworking, collaborative communities) and focus areas (Internet of things or Python, which is one of the most popular programming language for data science and especially machine learning). Technologic specific terms, such as Python, could also be connected to specific events as seen in Figure 2. For example, the use of the term, Python, only became relevant with the introduction of the Datahack for Financial Inclusion initiatives that launched at the end of 2017.

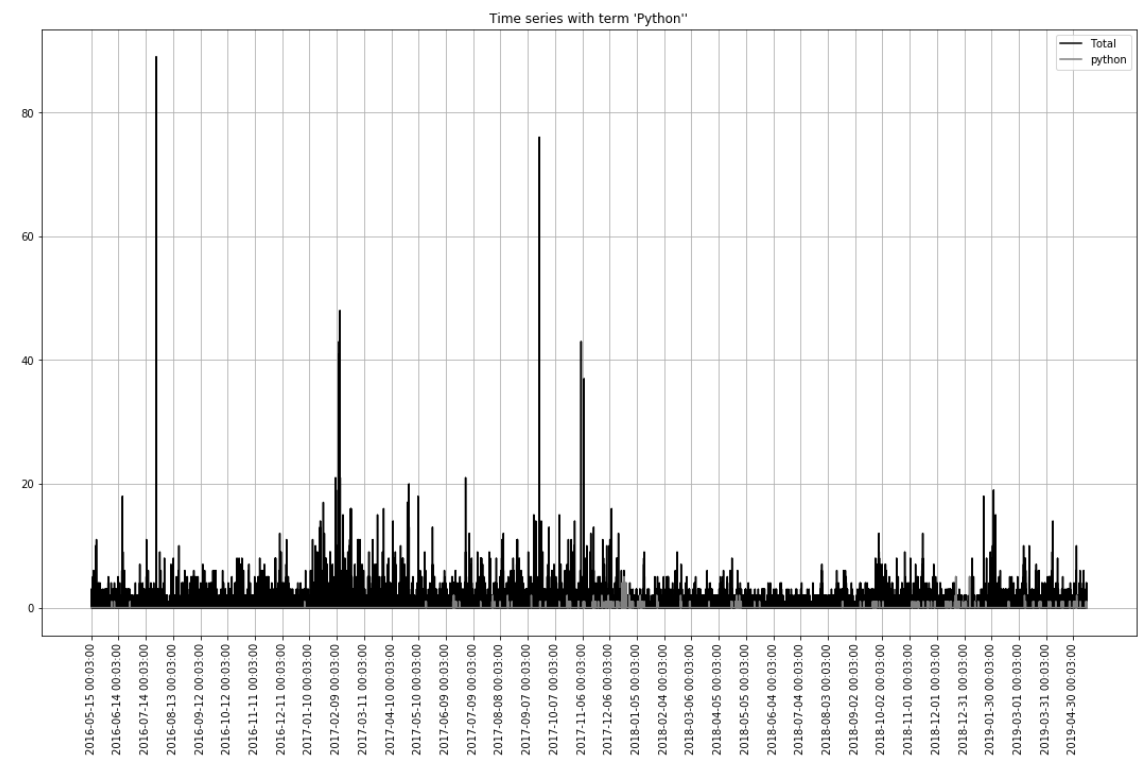

Figure 2. Time series with the term Python. 
By looking at most frequent terms, we can also see that many tweets contained the bigrams 'how to' and 'learn more', which indicates the distribution of tutorials or other material that is considered as a resource for learning in this entrepreneurial tech space. The fourth pattern we recognized is about campaigns that focus on creating and bundling discussions about specific topics. Examples range from \#talkbiz, a hashtag from Ghanaian entrepreneurs about everyday business questions and talking points to \#herfutureAfrica, a hashtag that specifically targets women in technology and encourages learning and female business activity. The last pattern highlighted that many tweets are targeted at different tech initiatives and programs. Some of those programs are locally bound, such as unlockingWAT courses at iSpace in Ghana, while others are African wide initiatives targeting specific entrepreneurial and social problems. The most frequent example in our dataset was \#datahack4fi (Datahack for Financial Inclusion), an initiative that provides courses and mentorships in data science to foster financial inclusion on the African continent.

\subsection{Geographic Information}

In our dataset, we retrieved geo data from two sources. First, from GPS information (if enabled by the account) and second from voluntary location details that were put in the profile information. We created a heat map of all accounts that tweeted about the three innovation hubs and were located on the African continent (see Figure 3). The first obvious observation was that the three cities the hubs are located in-namely Accra, Kampala and Lusaka-also mirrored the most activity in Africa. Above that, we can see interesting patterns that first showed clear regional affiliations and second highlighted hotspots of technological innovations in Africa. For Western Africa, the number of accounts tweeting about innovation hubs pointed towards three cities. While the first two-Accra and Kumasi-are the technological innovation centers of Ghana, Lagos hosts several innovation spaces and is a central force behind the growing digital economy on the continent [19]. In Eastern Africa, we saw Kampala as the most active location due to it being home to the Innovation Village hub. But similar to the western part of the continent, it is surrounded by technological hotspots, such as Kigali, Dar es Salaam and Nairobi. The later one sometimes being referred to as 'Silicon Savannah' [68] that has been a focus place for many stakeholders who are working in the technological innovation environment in Africa. For Southern Africa, the pattern of regional affiliation continued with the representation of Lusaka as home to the BongoHive hub and Ndola as the capital of the Copperbelt that is famous for its technical universities and engineering. Simultaneously, Johannesburg and Cape Town also stood out as two cities that host many accounts that actively take part in communicating about innovation hubs.

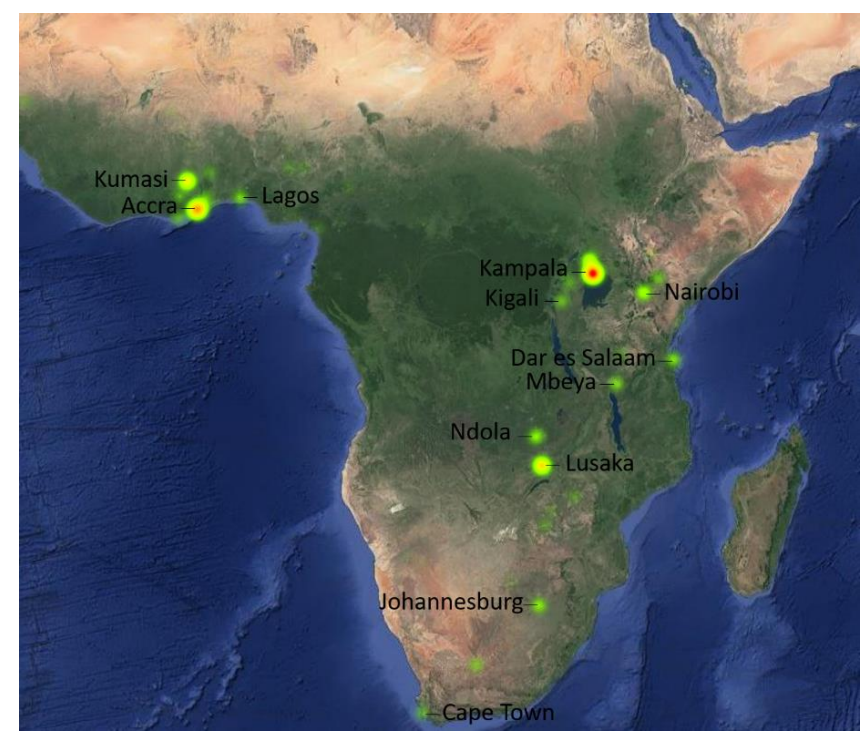

Figure 3. Geographical distribution of Tweets from Africa. 
What was evident about geographic location in our data set is the overwhelming domination of urban areas and the clear spotlight on certain hotspots that were not hosting one of the examined hubs but nonetheless seemed to be home to important stakeholders who participate and shape the digital innovation landscape around them.

\subsection{Network and Relations}

In addition to the above elaborated fundamental metrics, we also utilized methods from network science and visualized the connections that were created through mentions, replies and retweets. We created two network graphs, each giving us a different perspective on how accounts interacted with each other and how we could determine influence of stakeholders within online spaces. Figure 4 shows all accounts that have been mentioned at least 80 times within the three-year time span. This setting was not only used to improve the graphs' readability but also to filter out noise from the dataset that tampers with the core network's components. Mentions function as tags and gave us a good overview of different communities in our data by mapping the marked relations. The direction of connections is indicated by the curve of the link (clockwise away from source node). First, we adjusted the size of each node to the in-degree of mentions. Therefore, the larger the size, the more often the account was mentioned. Secondly, we delineated communities with the modularity algorithm [59] and assigned each community an individual color. Unsurprisingly, the investigated hubs form three unique communities with the hub's account at the center of the network. For our discussion on how to analyze influence in these communities, we evaluated the connecting elements between the three hubs as most important. We identified six major accounts that created linkages between the hubs. AfriLabs is functioning as an umbrella organization of African innovation hubs and organizes conferences, workshops and other platforms for communication. IHub, on the other hand, is one of Africa's first and most famous innovation hubs located in Nairobi that enjoys a high reputation and is a central player in the innovation sector of the continent. If we look at the complete data without filter, we can also see that there were many more hubs that acted like bridges between the three analyzed ones. J4Mtambalike is a key figure behind several good government and social driven tech initiatives as well as a partner at SparkSahara, a company that organizes East Africa's largest innovation and technology event (Sahara Spark). ABANAngels (African Business Angel Network) and VC4Africa are two organizations that work in the startup investment sector. From these connecting elements, we can derive at least two interesting insights: First, innovation hubs in Africa are very well connected to each other through both individual (hub-to-hub) and institutional (umbrella groups) connections. Second, there is an active startup investment community that engages with innovation hubs online and organizes various conferences and meetings to connect investors and digital entrepreneurs.

After looking at communities and key bridge actors between them, we analyzed replies that indicated the direct exchange of ideas and the discussion of topics that were relevant to all involved parties. Figure 5 shows all replies with a filter of 70 to capture the most active interactions. The size of the nodes represents the out-degree of replies, highlighting how many times an account replied to someone else's tweet. The curve of the connection again shows the direction (clockwise away from source node). We can see that the accounts of the three hubs were very active in replying to their own tweets indicating that they answer questions or clarify their initial distributed information. Because the number of interactions often did not say much about the scope and range of influence, we next calculated the betweenness centrality for each node. This method explains the position of accounts that determines control over information flow and highlights the stakeholders who have the most power over steering and directing information flows. Here we can see that it was indeed not the hubs' accounts but instead the three founders ('lukonga', CKJapheth', 'jkeyison') who held three out of the top four most influential positions in the network. We can also see that these three accounts were amongst the most active discussion participants (both input and target of questions or remarks) within their own respected hub community, indicating their status as representatives of their own local innovation community. Above that, we can identify one overarching connecting element 
that functioned as the key bridge between the three hubs and was already visible in the mention network above. 'J4Mtambalike' held the most influential position when it came to replies in the twitter online space by participating in intensive and regular exchanges with all three investigated hubs, and here especially with their founders. The account being closely linked to SparkSahara and actively communicating with umbrella initiatives, such as AfriLabs or ABANAngels, again highlighted core actors in the innovation niche and how they were connected through central initiatives or key people in addition to their ability to transfer information into their own communities.

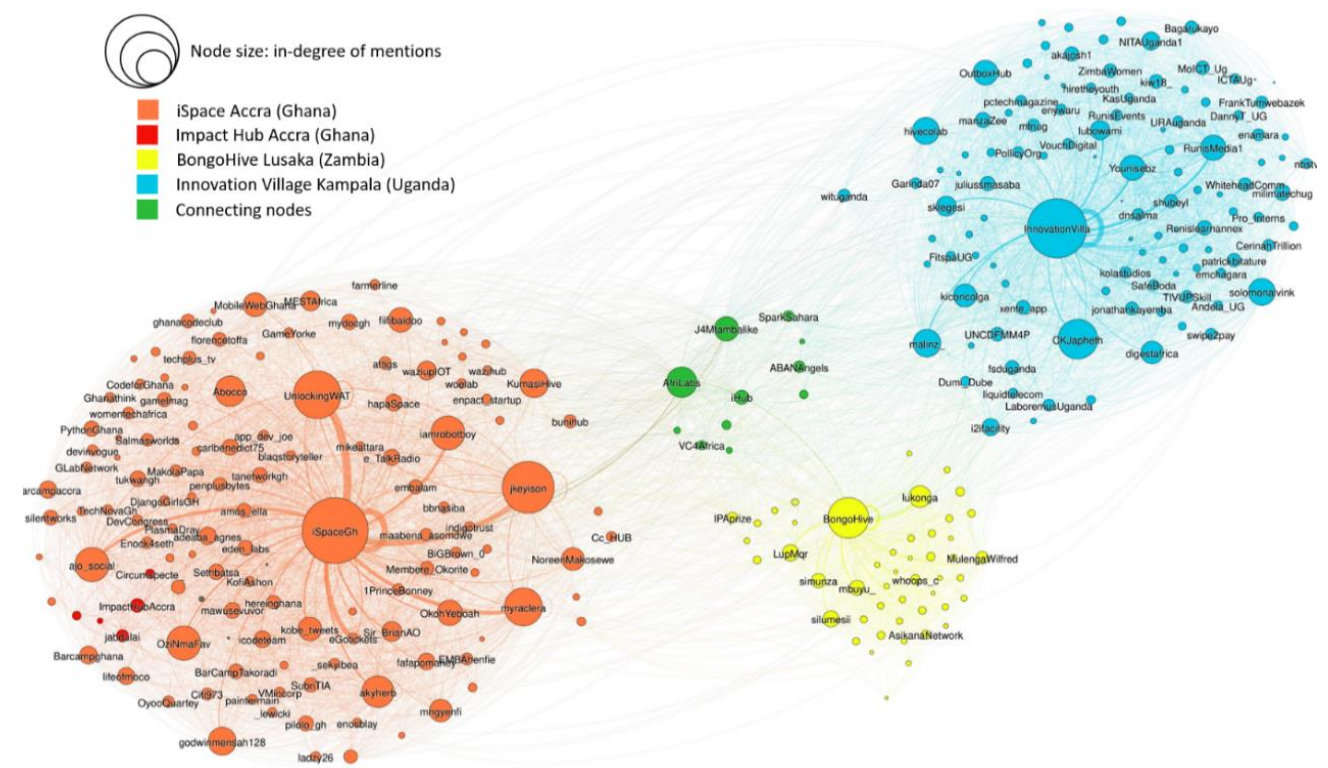

Figure 4. Mention network of Tweets.

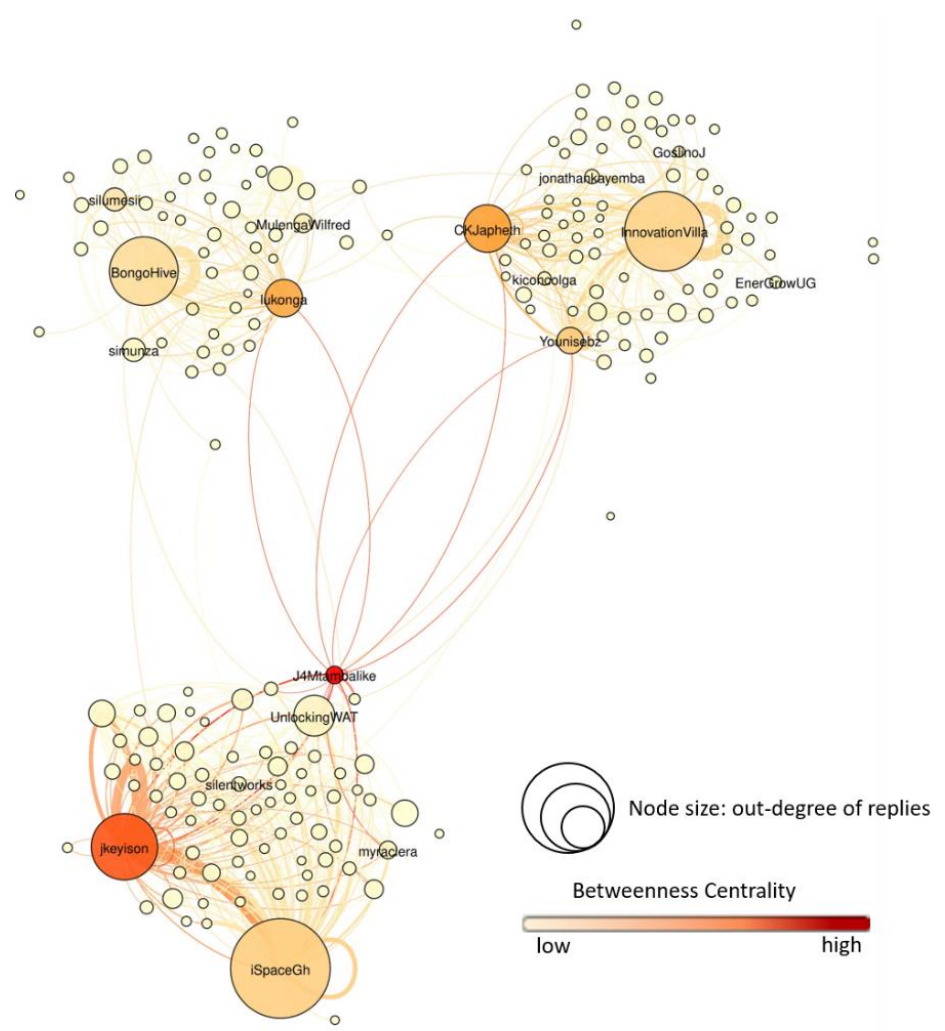

Figure 5. Replies network of Tweets. 


\section{Discussion}

Digital innovations play a key role in fostering sustainable transitions in the Global South. With a growing number of innovation spaces, the next wave of information and communication technology-based applications tackling sustainability challenges is prepared to come from local stakeholders, who are qualified to combine contextual implementation knowledge and technological capabilities. Accordingly, understanding how these production environments for digital innovations function gives new complementary insights into sustainability transitions. By combining our above elaborated theoretical frameworks for space and scale in networks and the concept of innovation intermediation, we want to discuss a number of insights that we draw from our analysis on online innovation spaces.

Innovation hubs in Africa lack relevant links between actors who form the core local network of the respected hub. Instead, the observable connections between the hub's communities are dominated by umbrella organizations or initiatives, hubs directly communicating with each other and hub's founders communicating with each other. Because we can clearly show that the hub's and founder's accounts also hold very dominant and influential positions within their own hub's integrated community, we can derive that they occupy intermediary roles. Especially the founders of innovation hubs share many links amongst each other and function as the whole networks' interconnecting nodes. These positions bridge their own community with other similarly structured communities across the continent and therefore, possess the ability to filter and steer discussion and talking points around digital technology and entrepreneurship. Our data also indicates that the connections between innovation hubs are fostered through umbrella groups, such as AfriLabs, or events, such as Sahara Spark, that again do not target the broad masses of local innovators but instead create links between key stakeholder, such as founders, and important group leaders. By shaping the innovation community's discussion and talking points, these highly influential positions, therefore, play a key role in niches in which new digital sustainability innovations are developed, tested and implemented. The same way Gliedt et al. [69] elaborated on innovation intermediaries as stakeholders who link various actions on different scales to influence sustainability development in uncertain and unstable environments, we found key players around innovation hubs possessed similar potential to influence large networks in digital technology niches due to their different communication and action radius. These findings also add new insights into previous research that conceptualizes innovation hubs through the framework of innovation intermediation. Friederici [16] highlighted that hubs in Africa assemble previous distant innovation actors and redefine new opportunities for them. We can now see that the assembly process does not only connect local actors to a locally bound innovation network but additionally links them to global network structures that are introduced and translated by key community facilitates, which actively shape ample and far-reaching global structures.

From a geographical perspective, our data analysis demonstrated a vast concentration of activity in urban areas, which is no surprise considering the advanced infrastructure for information and communication technologies in cities [70,71] as well as the hub's locations in urban areas. At the same time, many sustainability challenges in Africa are drawing on structures in rural areas and highlight digital solutions for agriculture or energy systems [72,73]. We, therefore, evaluate the trend of digital technology being shaped, developed and concentrated in urban areas as an interesting field for future research to determine how this sharp contrast of production and implementation environment affects sustainability outcomes.

For the field of transition research in the Global South, we wanted to highlight the importance of understanding where local born digital technology was created and in which niche environment it was tested. We found that all larger initiatives which were linked to or originated in at least one of the inspected hubs had strong affiliations with the sustainable development ideology and therefore, pushed the development of digital solutions in this context. Examples range from digital inclusion (Datahack for Financial Inclusion) to gender equality (UnlockingWAT). By bundling talking points under hashtags, such as \#herfutureAfrica, we can see how the hubs are active drivers behind creating 
inclusive environments for new innovations. In short, the connection to the sustainable development goals (SGDs) is heavily advertised and builds large foundations of those key initiatives. At the same time, the online space around hubs clearly showed their affiliation with their countries, highlighting the contextual innovation approach and their niche testing and implementation environments. These innovation niches across the continent of Africa have a lot in common, such as a focus on data science, financial and gender inclusion, start-up spirit and flexible co-working arrangements. Due to technology's missing ability to function in any given societal setting [74], it is of key importance to understand the production environment behind technological innovation. We, therefore, advocate for further research of inherent characteristics that are introduced due to the innovator's embeddedness in network structures, such as global hub communities and organizations and ideas that influence these very networks. We also want to promote the idea of understanding innovation hubs as niche environments that form local networks of like-minded innovators and entrepreneurs that are connected to a wide-ranging network of similar niches.

\section{Conclusions}

The purpose of this article was to combine transition research in Africa with a better understanding of digital innovation environments (innovation hubs). We conceptualized these innovation hubs as niches and innovation intermediaries that not only create communities to develop, test and implement new technology but also function as networks to discuss and form new ideas around innovations [16]. With methods from network science, we analyzed influence within and between these communities and showed how a relational network perspective provides new insights into the debate around production settings of digital technology.

Our key findings include the accentuation of key stakeholders, who occupy central positions in innovation networks. These positions enable them to connect similar global communities to each other. Through overarching and not locally embedded initiatives, these key stakeholders participate in wider discourses around innovative technology. The gained influence in return, allows them to steer and regulate discussions in their own local innovation environment. Furthermore, we saw a divide between urban and rural areas as well as a focus on the sustainable development ideology. With these key findings, we want to highlight two major insights for understanding niches for digital innovation. First, Science and Technology scholars have long highlighted the interdependency of technology and societal structures in the form of socio-technical system approaches [75] and the multi-level-perspective [4]. Case studies have shown that technologies are not created as neutral tools but instead contain specific social structures (e.g., network power within Wikipedia's editing structures [76]). We, therefore, advocate to analyze and understand the production environment of these technologies not only as a niche where these technologies are adopted and tested but also as a space where ideas and discourses shape, delineate and condition new innovations. Second, although we found clearly structured local communities around innovation hubs, their out and inbounded influence is managed through key stakeholders who possess the ability to weight and control innovation processes within their own niche. Due to the statistically significant impact of human capital on the adoption rate of technology [77], we want to emphasize the importance of understanding human network connections and the way new innovative ideas and discourses enter local innovation communities. This is especially important due to many information and communication scholars in the Global South highlighting the powerful societal transformation capability of technological innovations and its often-accompanied unintended side effects [78]. Because more and more transition scholars are concerned with the implementation of new technical systems in the Global South, we want to draw extra attention to the production environment of those technologies. As highlighted in this article, the production environment is of equal importance and at the same time, has not received the same attention in scholarly literature. We, therefore, call for more research on the innovators and their networks to better grasp the impact their technologies have once they are implemented and used. 
Author Contributions: D.S. was in charge of the theoretical conceptualization, coding, visualization, analyzation and discussion of the results and wrote the original draft. C.M. contributed to the theory chapter and reviewed and edited the original draft. All authors have read and agreed to the published version of the manuscript.

Funding: This research received no external funding.

Conflicts of Interest: The authors declare no conflict of interest.

\section{References}

1. Wieczorek, A.J.; Berkhout, F. Transitions to sustainability as societal innovations. In Principles of Environmental Sciences; Reijnders, L., Boersema, J., Eds.; Springer: Dordrecht, The Netherlands, 2009; pp. 503-512.

2. Grin, J.; Rotmans, J.; Schot, J. Transitions to Sustainable Development: New Directions in the Study of Long Term Transformative Change; Routledge: New York, NY, USA, 2010.

3. Wieczorek, A.J. Sustainability transitions in developing countries: Major insights and their implications for research and policy. Environ. Sci. Policy 2018, 84, 204-216. [CrossRef]

4. Geels, F.W. Technological transitions as evolutionary reconfiguration processes: A multi-level perspective and a case-study. Res. Policy 2002, 31, 1257-1274. [CrossRef]

5. Kemp, R.; Schot, J.; Hoogma, R. Regime shifts to sustainability through processes of niche formation: The approach of strategic niche management. Technol. Anal. Strateg. Manag. 1998, 10, 175-198. [CrossRef]

6. Geels, F.W. The multi-level perspective on sustainability transitions: Responses to seven criticisms. Environ. Innov. Soc. Transit. 2011, 1, 24-40. [CrossRef]

7. El Bilali, H.; Allahyari, M.S. Transition towards sustainability in agriculture and food systems: Role of information and communication technologies. Inf. Process. Agric. 2018, 5, 456-464. [CrossRef]

8. Martin, C.J.; Upham, P.; Budd, L. Commercial orientation in grassroots social innovation: Insights from the sharing economy. Ecol. Econ. 2015, 118, 240-251. [CrossRef]

9. Martin, C.J. The sharing economy: A pathway to sustainability or a nightmarish form of neoliberal capitalism? Ecol. Econ. 2016, 121, 149-159. [CrossRef]

10. Carvalho, L. Smart cities from scratch? A socio-technical perspective. Camb. J. Reg. Econ. Soc. 2014, 8, 43-60. [CrossRef]

11. Mah, D.N.Y.; Wu, Y.Y.; Ip, J.C.M.; Hills, P.R. The role of the state in sustainable energy transitions: A case study of large smart grid demonstration projects in Japan. Energy Policy 2013, 63, 726-737. [CrossRef]

12. Jiménez, A. Inclusive innovation from the lenses of situated agency: Insights from innovation hubs in the UK and Zambia. Innov. Dev. 2019, 9, 41-64.

13. Giuliani, D.; Ajadi, S. 618 Active Tech Hubs: The Backbone of AFRICA'S Tech Ecosystem. Available online: https://www.gsma.com/mobilefordevelopment/blog/618-active-tech-hubs-the-backbone-of-africastech-ecosystem/ (accessed on 14 January 2020).

14. Bright, J.; Hruby, A. The Next Africa: An Emerging Continent Becomes A Global Powerhouse; Macmillan: New York, NY, USA, 2015.

15. Murphy, J.T.; Carmody, P. Africa's Information Revolution: Technical Regimes and Production Networks in South Africa and Tanzania; John Wiley \& Sons: Hoboken, NJ, USA, 2015.

16. Friederici, N. Innovation Hubs in Africa: Assemblers of Technology Entrepreneurs; Oxford University Press: Oxford, UK, 2016.

17. Friederici, N. Grounding the Dream of African Innovation Hubs: Two Cases in Kigali. J. Dev. Entrep. 2018, 23, 1850012. [CrossRef]

18. Jiménez, A.; Zheng, Y. Tech hubs, innovation and development. Inf. Technol. Dev. 2018, 24, 95-118. [CrossRef]

19. Littlewood, D.C.; Kiyumbu, W.L. "Hub" organisations in Kenya: What are they? What do they do? And what is their potential? Technol. Forecast. Soc. Chang. 2018, 131, 276-285. [CrossRef]

20. Burt, R.S.; Kilduff, M.; Tasselli, S. Social network analysis: Foundations and frontiers on advantage. Annu. Rev. Psychol. 2013, 64, 527-547. [CrossRef] [PubMed]

21. Fritsch, M.; Kauffeld-Monz, M. The impact of network structure on knowledge transfer: An application of social network analysis in the context of regional innovation networks. Ann. Reg. Sci. 2010, 44, 21. [CrossRef]

22. Fleming, L.; Colfer, L.; Marin, A.; McPhie, J. Why the valley went first: Agglomeration and emergence in regional inventor networks. In Proceedings of the Annual Meeting of the Academy of Management, New Orleans, LA, USA, 15 August 2004. 
23. Java, A.; Song, X.; Finin, T.; Tseng, B. Why we twitter: Understanding microblogging usage and communities. In Proceedings of the 9th WebKDD and 1st SNA-KDD 2007 Workshop on Web Mining and Social Network Analysis, San Jose, CA, USA, 12 August 2007; pp. 56-65.

24. Madaio, M.A.; Grinter, R.E.; Finin, T.; Zegura, E.W. Experiences with MOOCs in a West-African technology hub. In Proceedings of the Eighth International Conference on Information and Communication Technologies and Development ICTD, Ann Arbor, MI, USA, 3-6 June 2016; pp. 1-4.

25. Bayen, M.; Giuliani, D. Africa: A look at the 442 active tech hubs of the continent. Mobile for Development. 22 March 2018. Available online: https://www.gsma.com/mobilefordevelopment/blog-2/africa-a-look-at-the442-active-tech-hubs-of-the-continent/ (accessed on 14 January 2020).

26. Moraa, H.; Gathege, D. How ICT hubs models have impacted on the technology entrepreneurship development. In Proceedings of the Sixth International Conference on Information and Communications Technologies and Development: Notes-Volume 2, Cape Town, South Africa, 7 December 2013; pp. 100-103.

27. Kelly, T.; Firestone, R. How tech hubs are helping to drive economic growth in Africa. In World Development Report 2016 Digital Dividends; World Bank Publications: Washington, DC, USA, 2016; p. 13.

28. Amankwah-Amoah, J. Technological revolution, sustainability, and development in Africa: Overview, emerging issues, and challenges. Sustain. Dev. 2019, 27, 910-922. [CrossRef]

29. Soumare, M.; Velluet, Q.; Galtier, M. Tech Hubs not Hype. Available online: https://www.pressreader.com/ france/the-africa-report/20191215/281522227977010 (accessed on 14 January 2020).

30. Obeysekare, E.; Mehta, K.; Maitland, C. Defining success in a developing country's innovation ecosystem: The case of Rwanda. In Proceedings of the IEEE Global Humanitarian Technology Conference (GHTC), IEEE, San Jose, CA, USA, 19-22 October 2017; pp. 1-7.

31. Jiménez, A.; Roberts, T. Decolonising Neo-Liberal Innovation: Using the Andean Philosophy of 'Buen Vivir'to Reimagine Innovation Hubs. In International Conference on Social Implications of Computers in Developing Countries; Springer: Cham, Switzerland, 2019; pp. 180-191.

32. Lawhon, M.; Murphy, J.T. Socio-technical regimes and sustainability transitions: Insights from political ecology. Prog. Hum. Geogr. 2012, 36, 354-378. [CrossRef]

33. Hansen, T.; Coenen, L. The geography of sustainability transitions: Review, synthesis and reflections on an emergent research field. Environ. Innov. Soc. Transit. 2015, 17, 92-109. [CrossRef]

34. Bridge, G.; Bouzarovski, S.; Bradshaw, M.; Eyre, N. Geographies of energy transition: Space, place and the low-carbon economy. Energy Policy 2013, 53, 331-340. [CrossRef]

35. Truffer, B.; Coenen, L. Environmental innovation and sustainability transitions in regional studies. Reg. Stud. 2012, 46, 1-21. [CrossRef]

36. Boschma, R.; Coenen, L.; Frenken, K.; Truffer, B. Towards a theory of regional diversification: Combining insights from Evolutionary Economic Geography and Transition Studies. Reg. Stud. 2017, 51, 31-45. [CrossRef]

37. Power, M.; Newell, P.; Baker, L.; Bulkeley, H.; Kirshner, J.; Smith, A. The political economy of energy transitions in Mozambique and South Africa: The role of the Rising Powers. Energy Res. Soc. Sci. 2016, 17, 10-19. [CrossRef]

38. Murphy, J.T. Human geography and socio-technical transition studies: Promising intersections. Environ. Innov. Soc. Transit. 2015, 17, 73-91. [CrossRef]

39. Malpas, J. Putting space in place: Philosophical topography and relational geography. Environ. Plan. D Soc. Space 2012, 30, 226-242. [CrossRef]

40. Herod, A. Scale: The local and the global. Key Concepts Geogr. 2003, 229, 234.

41. Murray, W.E.; Overton, J. Geographies of Globalization; Routledge: London, UK, 2014.

42. Schmitt, D. Production Environments of Digital Innovations: A Scalar Perspective on Cultural Legitimacy in Zambian Coding Networks. Perspect. Glob. Dev. Technol. 2019, 1, 1-26. [CrossRef]

43. Schmidt, J.H. Twitter and the rise of personal publics. In Twitter and Society; Peter Lang Publishing: New York, NY, USA, 2014; pp. 3-14.

44. Weller, K.; Bruns, A.; Burgess, J.; Mahrt, M.; Puschmann, C. Twitter and Society; Peter Lang Publishing: New York, NY, USA, 2014.

45. Himelboim, I.; Sweetser, K.D.; Tinkham, S.F.; Cameron, K.; Danelo, M.; West, K. Valence-based homophily on Twitter: Network analysis of emotions and political talk in the 2012 presidential election. New Media Soc. 2016, 18, 1382-1400. [CrossRef] 
46. Jurdak, R.; Zhao, K.; Liu, J.; AbouJaoude, M.; Cameron, M.; Newth, D. Understanding human mobility from Twitter. PLoS ONE 2015, 10, e0131469. [CrossRef]

47. Mejova, Y.; Weber, I.; Macy, M.W. (Eds.) Twitter: A Digital Socioscope; Cambridge University Press: Cambridge, UK, 2015.

48. Chatfield, A.T.; Brajawidagda, U. Twitter early tsunami warning system: A case study in Indonesia's natural disaster management. In Proceedings of the 46th Hawaii International Conference on System Sciences, IEEE Computer Society, Wailea, HI, USA, 7-10 January 2013; pp. 2050-2060.

49. Shimada, K.; Inoue, S.; Maeda, H.; Endo, T. Analyzing tourism information on twitter for a local city. In Proceedings of the First ACIS International Symposium on Software and Network Engineering, IEEE Computer Society, Seoul, Korea, 19-20 December 2011; pp. 61-66.

50. Chae, B.K. Insights from hashtag\# supplychain and Twitter Analytics: Considering Twitter and Twitter data for supply chain practice and research. Int. J. Prod. Econ. 2015, 165, 247-259.

51. Serrat, O. Social Network Analysis. In Knowledge Solutions; Springer: Singapore, 2017.

52. Bruns, A.; Moe, H. Structural layers of communication on Twitter. In Twitter and Society; Peter Lang Publishing: New York, NY, USA, 2014; Volume 89, pp. 15-28.

53. Kenett, D.Y.; Havlin, S. Network science: A useful tool in economics and finance. Mind Soc. 2015, 14, $155-167$. [CrossRef]

54. Cohen, R.; Havlin, S. Complex Networks: Structure, Robustness and Function; Cambridge University Press: Cambridge, UK, 2010.

55. Brandes, U.; Robins, G.; McCranie, A.; Wasserman, S. What is network science? Netw. Sci. 2013, 1, 1-15. [CrossRef]

56. Robins, G. Doing Social Network Research: Network-Based Research Design for Social Scientists; Sage: Thousand Oaks, CA, USA, 2015.

57. Collobert, R.; Weston, J.; Bottou, L.; Karlen, M.; Kavukcuoglu, K.; Kuksa, P. Natural language processing (almost) from scratch. J. Mach. Learn. Res. 2011, 12, 2493-2537.

58. Jacomy, M.; Venturini, T.; Heymann, S.; Bastian, M. ForceAtlas2, a continuous graph layout algorithm for handy network visualization designed for the Gephi software. PLoS ONE 2014, 9, e98679. [CrossRef] [PubMed]

59. Newman, M.E. Modularity and community structure in networks. Proc. Natl. Acad. Sci. USA 2006, 103, 8577-8582. [CrossRef] [PubMed]

60. Blondel, V.D.; Guillaume, J.L.; Lambiotte, R.; Lefebvre, E. Fast unfolding of communities in large networks. J. Stat. Mech. Theory Exp. 2008, 2008, P10008. [CrossRef]

61. Brandes, U. A faster algorithm for betweenness centrality. J. Math. Sociol. 2001, 25, 163-177. [CrossRef]

62. Riquelme, F.; González-Cantergiani, P. Measuring user influence on Twitter: A survey. Inf. Process. Manag. 2016, 52, 949-975. [CrossRef]

63. Gayo-Avello, D. Nepotistic relationships in twitter and their impact on rank prestige algorithms. Inf. Process. Manag. 2013, 49, 1250-1280. [CrossRef]

64. Bastian, M.; Heymann, S.; Jacomy, M. Gephi: An open source software for exploring and manipulating networks. In Proceedings of the Third International AAAI Conference on Weblogs and Social Media, San Jose, CA, USA, 17-20 May 2009.

65. Oldham, P.; Hall, S.; Burton, G. Synthetic biology: Mapping the scientific landscape. PLoS ONE 2012, 7, e34368. [CrossRef]

66. Bruns, A. How long is a tweet? Mapping dynamic conversation networks on Twitter using Gawk and Gephi. Inf. Commun. Soc. 2012, 15, 1323-1351. [CrossRef]

67. Heymann, S.; Le Grand, B. Visual analysis of complex networks for business intelligence with gephi. In Proceedings of the 2013 17th International Conference on Information Visualisation IEEE, London, UK, 16-18 July 2013; pp. 307-312.

68. Graham, M.; Mann, L. Imagining a silicon Savannah? Technological and conceptual connectivity in Kenya's BPO and software development sectors. Electron. J. Inf. Syst. Dev. Ctries. 2013, 56, 1-19. [CrossRef]

69. Gliedt, T.; Hoicka, C.E.; Jackson, N. Innovation intermediaries accelerating environmental sustainability transitions. J. Clean. Prod. 2018, 174, 1247-1261. [CrossRef]

70. Furuholt, B.; Kristiansen, S. A rural-urban digital divide? Regional aspects of Internet use in Tanzania. Electron. J. Inf. Syst. Dev. Ctries. 2007, 31,1-15. [CrossRef] 
71. Salemink, K.; Strijker, D.; Bosworth, G. Rural development in the digital age: A systematic literature review on unequal ICT availability, adoption, and use in rural areas. J. Rural. Stud. 2017, 54, 360-371. [CrossRef]

72. Prinsloo, G.; Dobson, R.; Mammoli, A. Smart Village Load Planning Simulations in Support of Digital Energy Management for Off-grid Rural Community Microgrids. Curr. Altern. Energy Spec. Issue Standalone Renew. Energy Syst. Remote Area Power Suppl. 2017, 12, 1-22. [CrossRef]

73. Dlodlo, N.; Kalezhi, J. The internet of things in agriculture for sustainable rural development. In Proceedings of the 2015 International Conference on Emerging Trends in Networks and Computer Communications (ETNCC), IEEE, London, UK, 17-20 May 2015; pp. 13-18.

74. Leonardi, P.M. Materiality, sociomateriality, and socio-technical systems: What do these terms mean? How are they different? Do we need them. In Materiality and Organizing: Social Interaction in a Technological World; Oxford University Press: Oxford, UK, 2012; p. 25.

75. Trist, E. The evolution of socio-technical systems. Occas. Pap. 1981, 2, 1981.

76. Graham, M.; Straumann, R.K.; Hogan, B. Digital divisions of labor and informational magnetism: Mapping participation in Wikipedia. Ann. Assoc. Am. Geogr. 2015, 105, 1158-1178. [CrossRef]

77. Danquah, M.; Amankwah-Amoah, J. Assessing the relationships between human capital, innovation and technology adoption: Evidence from sub-Saharan Africa. Technol. Forecast. Soc. Chang. 2017, 122, 24-33. [CrossRef]

78. Unwin, T. Reclaiming Information and Communication Technologies for Development; Oxford University Press: Oxford, UK, 2017.

(C) 2020 by the authors. Licensee MDPI, Basel, Switzerland. This article is an open access article distributed under the terms and conditions of the Creative Commons Attribution (CC BY) license (http://creativecommons.org/licenses/by/4.0/). 